\title{
The Prediction of Drying Uniformity in Tray Dryer System using CFD Simulation
}

\author{
Suhaimi Misha, Sohif Mat, Mohd Hafidz Ruslan, Kamaruzzaman Sopian, and Elias Salleh
}

\begin{abstract}
Tray dryer is the most extensively used because of its simple and economic design. In a tray dryer, more products can be loaded as the trays are arranged at different levels. The product is spread out on trays at an acceptable thickness. The drawback of this dryer is non-uniformity in the desired moisture content of end product due to poor air flow distribution in the drying chamber. Computational fluid dynamics (CFD) is used extensively because of its capability to solve equations for the conservation of mass, momentum, and energy using numerical methods to predict the temperature, velocity, and pressure profiles. This research is to predict drying uniformity of new design of the commercial tray dryer for agricultural product. The temperature and velocity profile, streamline and velocity on each tray were analyzed to study the uniformity of the drying. The 3D simulation is done to represent the actual model. Generally the temperatures are considered uniform for all trays. However the average air velocity at several trays which is at tray number $1,7,8$ and 15 are much higher than others tray. The rest of the trays are look more uniform. The average air velocity above the tray is about 0.38 $\mathbf{m} / \mathbf{s}$.
\end{abstract}

Index Terms-Drying simulation, tray dryer, uniform drying.

\section{INTRODUCTION}

The tray dryer is widely used in a variety of applications because of its simple design and capability to dry products at high volume. However, the greatest drawback of the tray dryer is uneven drying because of poor airflow distribution in the drying chamber. Several designs and methods can be implemented to improve tray dryer performance, increases quality of dried product and produces uniform drying as reported by Misha et al. [1]. Nowadays, given the increase in computing power, the application of Computational Fluid Dynamics (CFD) can be a valuable tool for engineering design and analysis of solving complex fluid flow, addressing heat and mass transfer phenomena, aiding in the better design of tray dryers and produce high quality of dried product. CFD simulation is used extensively because of its capability to solve equations for the conservation of mass, momentum, and energy using numerical methods to predict the

Manuscript received July 15, 2013; revised September 16, 2013. This work was supported by the Kementerian Pendidikan Malaysia under Grant PRGS/1/12/TK07/UKM/02/2, Universiti Kebangsaan Malaysia and Universiti Teknikal Malaysia Melaka. The Prediction of Drying Uniformity in Tray Dryer System Using CFD Simulation.

Suhaimi Misha is with the Faculty of Mechanical Engineering, UniversitiTeknikal Malaysia Melaka, Hang Tuah Jaya, 76100 Durian Tunggal, Melaka (e-mail: suhaimimisha@ utem.edu.my).

Sohif Mat, Mohd Hafidz Ruslan, Kamaruzzaman Sopian, and Elias Salleh are with the Solar Energy Research Institute, Universiti Kebangsaan Malaysia, 43600 Bangi, Selangor, Malaysia (e-mail:drsohif@gmail.com, hafidz@pkrisc.cc.ukm.my, ksopian@eng.ukm.my, elsall06@gmail.com). temperature, velocity, and pressure profiles in the drying chamber.

Dionissios and Adrian-Gabriel Ghious [2] studied the numerical simulation inside a drying chamber. A set of measurements was obtained experimentally above one single tray to validate the model. The validation between the measured data and the simulation results by CFD shows that the standard $\mathrm{k}-\mathrm{e}$ model is the most adequate turbulence model. An industrial batch-type tray dryer for drying fruits has been designed and constructed by Mathioulakis et al. [3]. CFD is used to simulate the air pressure and the air velocity profiles in the drying chamber. The result shows that a variation of final moisture content occurs in several trays. Comparison of the simulation result by the CFD and experimental data shows a strong correlation between drying rate and air velocity.

Mirade [4] using a two-dimensional CFD model with time-dependent boundary conditions to investigate the homogeneity of the distribution of the air velocity in an industrial meat dryer for several low and high levels of the ventilation cycle. All airflow simulations are consistent with the heterogeneity of drying usually observed in practice. The product is represented by solid rectangular object. Chr. Lamnatou et al. [5] developed and investigated a numerical model of heat and mass transfer during convective drying of a porous body using the finite-volume method. The results show that the aspect ratio of the drying plate and the flow separation influence the flow field and heat/mass transfer coefficients. The increase in the contact surfaces between the porous body and air also contributes to the improvement of drying behavior.

Some product can be treated as solid (non-porous) material. However most of the products are represented by porous media. The comparison of CFD simulation result between porous and solid product in drying application has been done by Misha et al. [6]. It was found that by using porous product the overall velocities in the drying chamber are lower than solid product since some of the hot air stream pass through the porous product.

Design optimization of a drying chamber is necessary to achieve higher heat/mass transfer rates and uniform drying by avoiding an unfavorable aerodynamic phenomenon in the chamber. The objective of this research is to predict the drying uniformity for the new tray dryer design for agricultural product. The CFD is used as a tool to predict the airflow distribution in the drying chamber.CFD has also been widely used in food industry to investigate the flow pattern of the air in the drying chamber [7], [8]. Uniform airflow distribution in drying chamber is very important because it gave significant effect on the efficiency and the homogeneity of the product being dried. The use of a desiccant material in drying applications has several advantages, including the improvement in the uniformity of dried products [9]. 


\author{
Nomenclature \\ $C, D$ prescribed matrices $\sigma_{k}$ turbulent Prandtl numbers for $k$ \\ $C_{0}, C_{1}$ empirical coefficients $\sigma_{\varepsilon}$ turbulent Prandtl numbers for $\varepsilon$ \\ $C_{i j}$ prescribed matrices $E$ total energy \\ Dij mass diffusion coefficient $v_{i}$ velocity vector \\ $P$ density of fluid $v_{\text {mag }}$ velocity magnitude \\ $K$ turbulent kinetic energy $\left(\tau_{i j}\right)_{\text {eff }}$ deviatoric stress tensor \\ $\varepsilon$ rate of dissipation $p$ pressure \\ $\mu$ dynamic viscosity $P r_{t}$ Prandtl number \\ $\mu_{t}$ turbulent viscosity $T$ temperature \\ $G_{k}$ generation of turbulent kinetic energy $c_{p}$ specific heat capacity at constant \\ due to the mean velocity gradients pressure \\ $G_{b}$ generation of turbulent kinetic energy $u$ velocity magnitude in $x$ direction \\ due to buoyancy $t$ time \\ $Y_{M}$ contribution of the fluctuating dilatation $S_{k}, S_{\varepsilon}, S_{h}$ user-defined source terms \\ in compressible turbulence to the overall $S_{i}$ source term for $i$ th momentum \\ dissipation rate equation \\ $C_{1 \varepsilon}, C_{2 \varepsilon}, C_{3 \varepsilon}$ constants used in turbulent model
}

\section{Methods AND SimUlation}

\section{A. Design of a New Drying Chamber}

The constructed dryer system is designed to dry any agricultural product at high volume. The space of drying area is approximately $25 \mathrm{~m}^{2}$. The wall of the dryer system was constructed using $6 \mathrm{~cm}$ thick hollow polycarbonate with a hollow space in the middle measuring $4 \mathrm{~cm}$ deep. The drying chamber dimension is approximately $2 \mathrm{~m} \times 3 \mathrm{~m} \times 1.7 \mathrm{~m}$ (width, length, and height, respectively).The layout of the drying camber is shown in Fig. 1. The dryer system consists of 7 levels of trays system and each level has 3 separated trays. The end space in the drying chamber is used to occupy operator for loading or unloading the product to the last column of trays. The positions of trays in the drying chamber are shown in Fig. 2. The thickness of the products in each tray is approximately $6 \mathrm{~cm}$. The velocity and temperature distribution were studied to predict the drying uniformity.

\section{B. Basic Governing Equations}

The mass, momentum and energy conservation result in the continuity, Navier-Stokes and energy equation, respectively [10]. The turbulent model is used in this CFD simulation. The turbulent kinetic energy, $k$, and its rate of dissipation, $\varepsilon$, are calculated from the following transport equations:

$$
\begin{gathered}
\frac{\partial}{\partial t}(\rho k)+\frac{\partial}{\partial x_{i}}\left(\rho k u_{i}\right)=\frac{\partial}{\partial x_{j}}\left[\left(\mu+\frac{\mu_{t}}{\sigma_{k}}\right) \frac{\partial k}{\partial x_{j}}\right] G_{k}+ \\
G_{b}-\rho \varepsilon-Y_{M}+S_{k} \\
\frac{\partial}{\partial t}(\rho \varepsilon)+\frac{\partial}{\partial x_{i}}\left(\rho \varepsilon u_{i}\right)=\frac{\partial}{\partial x_{j}}\left[\left(\mu+\frac{\mu_{t}}{\sigma_{\varepsilon}}\right) \frac{\partial \varepsilon}{\partial x_{j}}\right]+ \\
C_{1 \varepsilon} \frac{\varepsilon}{k}\left(G_{k}+C_{3 \varepsilon} G_{b}\right)-C_{2 \varepsilon} \rho \frac{\varepsilon^{2}}{k}+S_{\varepsilon}
\end{gathered}
$$

Convective heat and mass transfer modeling in the $\mathrm{k}-\varepsilon$ models is given by the following equation [11]:

$$
\begin{aligned}
\frac{\partial}{\partial t}(\rho E)+\frac{\partial}{\partial x_{i}} & {\left[u_{i}(\rho E+p)\right] } \\
& =\frac{\partial}{\partial x_{i}}\left[\left(k+\frac{c_{p} \mu_{t}}{P r_{t}}\right) \frac{\partial T}{\partial x_{i}}+u_{i}\left(\tau_{i j}\right)_{e f f}\right]+S_{h}
\end{aligned}
$$

Product trays are assumed as a porous media for airflow. Porous media are modeled by the addition of a momentum source term to the standard fluid flowequations. The source term is composed of two parts: a viscous loss term and an inertial loss term.

$$
S_{i}-\left(\sum_{j=1}^{3} D_{i j} \mu v_{j} \sum_{j=1}^{3} c_{i j} \frac{1}{2} \rho v_{m a g} v_{i}\right)
$$

\section{Simulation Details}

The numerical finite volume method, as used in Fluent 12.1, has been used to solve equations and to build a numerical model based on an unstructured 3D mesh by tetrahedral cells. The geometrical configurations were displayed in Fig. 2. The pattern of air stream in the drying chamber is important and since there was no variable condition in this study, the simulation was carried out in steady state condition. The plane 1 was selected (Fig. 1.) to study and analyse the velocity and temperature in the drying chamber. Plane 1 is located in between of two axial fans, which considered as the weak zone compared to others areas in the drying chamber. The set-up of boundary conditions were defined as followings:

- Inlet 1: air mass flow rate $0.5843 \mathrm{~kg} / \mathrm{s}$ (approximately velocity of $3 \mathrm{~m} / \mathrm{s}$ normal to air inlet) and air temperature of $65^{\circ} \mathrm{C}$.

- Inlet 2: air mass flow rate $0.29215 \mathrm{~kg} / \mathrm{s}$ (half of the inlet 1 but give same velocity $3 \mathrm{~m} / \mathrm{s}$ ) and air temperature of $65^{\circ} \mathrm{C}$.

- Outlet : Assuming gauge pressure $=0$ at the outlet.

- Porous media: The trays were assumed as porous media with $10 \%$ porosity.

- Wall: Heat transfer coefficient of the chamber wall and environmental conditions were defined. The environment 
temperature is assumed at $33^{\circ} \mathrm{C}$ and temperature at the top roof is $55^{\circ} \mathrm{C}$ (contact to the heat source from radiation). The bottom surface is assumed as no heat loss. Only half of the drying chamber was analysed since the shape is symmetryby defining the symmetry surface to the middle boundary.

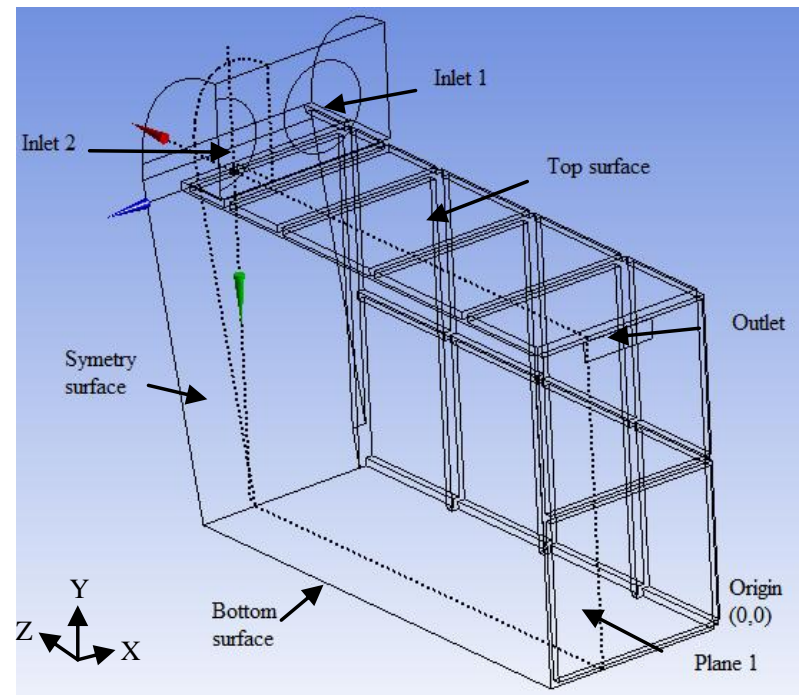

Fig. 1. Drying chamber layout and the boundary condition.

\section{RESULT AND DISCUSSION}

Even though the simulation was done in three dimensions but the analysis was carried out at plane 1 as indicated in Fig. 1. Several planes have been studied but plane 1 is considered as poor zone in term of hot air distribution because the position in between the two fans. The simulation was carried out and the temperature distribution profile at plane 1 is shown in Fig. 2. The hot air temperature from inlet is $65^{\circ} \mathrm{C}$. It was found that the temperature for most of the trays was in the range of 64.4 to $65^{\circ} \mathrm{C}$ except for the lowest tray. The temperature for lowest tray was in the range of 63.8 to $64.4^{\circ} \mathrm{C}$. The difference of temperature about $1.2^{\circ} \mathrm{C}$ among the trays is considered small and it can be assumed that the design successfully achieved the reasonable uniform air temperature in the drying chamber.

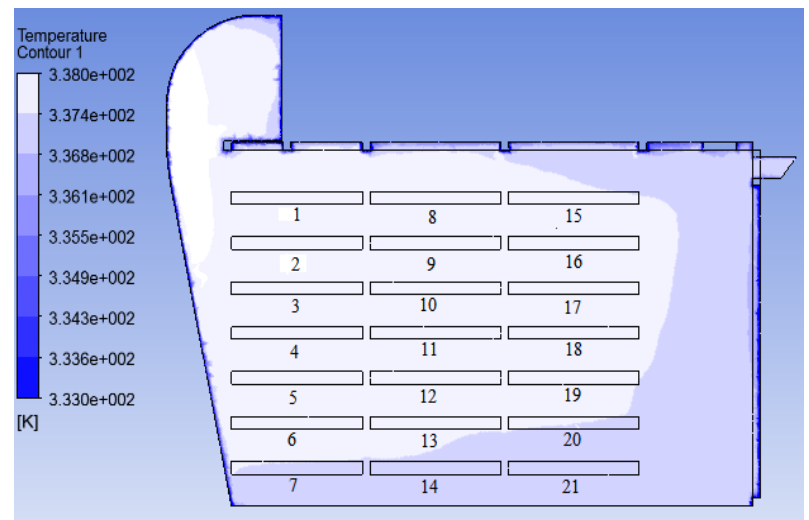

Fig. 2. Tray position and temperature distribution profiles at plane 1.

In drying application, the temperature, velocity and humidity of drying air condition gave significant effect to the drying process. In this simulation study, only temperature and velocity of the drying air can be analysed since the equation used is not involved humidity. Humidity analysis will be done in the future experimental work. The velocity profile at plane 1 is shown in Fig. 3. Generally the velocity around the tray is very low in the range of 0 to $0.375 \mathrm{~m} / \mathrm{s}$. The inlet is not located at plane 1 since the position of this plane is in between the two fans as shown in Fig. 1. Therefore the velocity is also low at the beginning and increasing after it collided to the curve wall. Fig. 4 show the velocity profile at another plane which is cut at the center of the inlet 1 . It shows that the velocity achieved the maximum value at $3 \mathrm{~m} / \mathrm{s}$ as determined in the inlet boundary condition. The temperature and velocity profile at plane 1 can't be done in $2 \mathrm{D}$ since the inlet position is not located in this plane. This is the main reason why the simulation was carried out in $3 \mathrm{D}$.

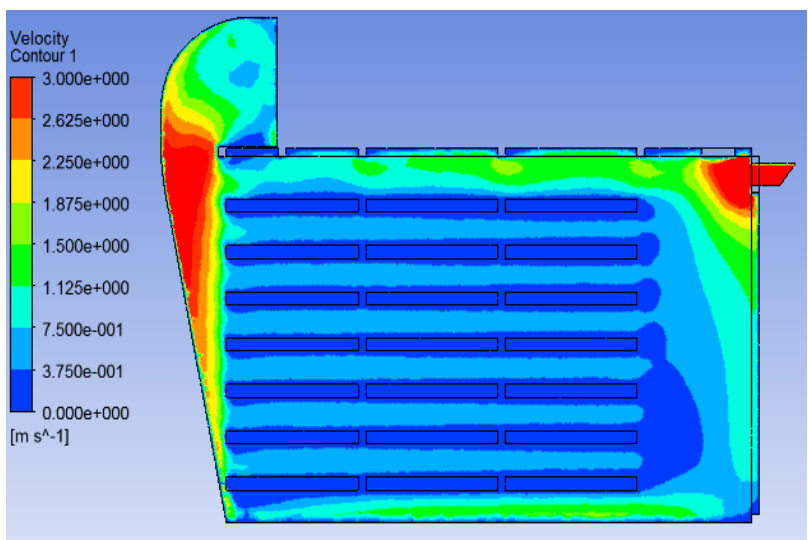

Fig. 3. Velocity distribution profiles at plane 1 (in between 2 fans).

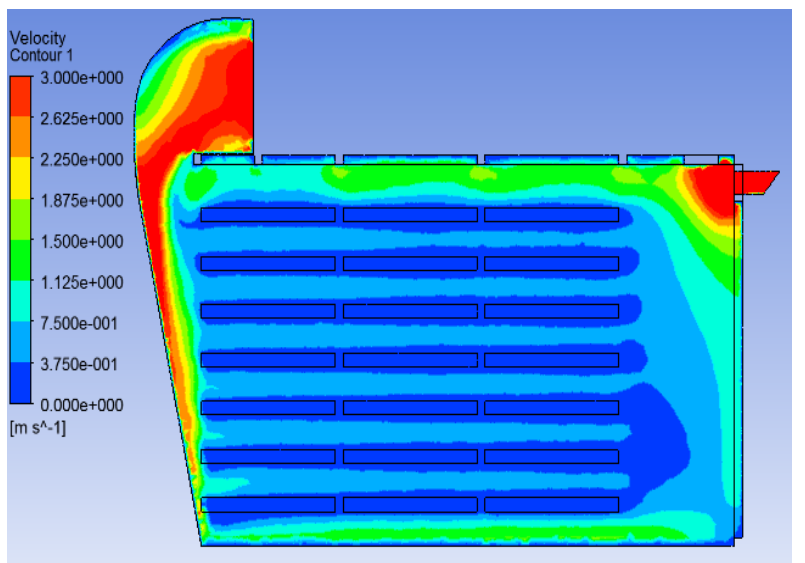

Fig. 4. Velocity distribution profiles at plane 2 (center of inlet 1).

The air velocity above the trays are very important to carries the moisture from the product. The air velocity along the trays at plane 1 was studied in this simulation. The air velocity profile at $2.5 \mathrm{~cm}$ above the trays for each tray is shown in Fig. 5. Generally the average air velocities at trays 1 to 7 are higher than other trays since the positions are close to the inlet. As the drying air passes over the trays, the air velocity would decrease except for tray number 8 and 15. At trays 8 and 15 the velocities are increase because it closes to the air outlet. The minimum air velocity above the tray is around $0.28 \mathrm{~m} / \mathrm{s}$ at the last column of tray. The average air velocity above the trays is about $0.38 \mathrm{~m} / \mathrm{s}$. The high velocity at the first column of trays can't be avoided because it closes to the inlet with the maximum velocity of $1.1 \mathrm{~m} / \mathrm{s}$. The variation of final moisture content of the product may occur based on the velocity profile. The high air velocity at the above product (tray) will make the product dry faster compared to the product with low air velocity. 
The temperature profiles in the drying chamber can be considered as uniform because the temperature drop is very small around $1.2^{\circ} \mathrm{C}$ only. However the air velocities above the trays are not uniform. The product at tray number $1,7,8$ and 15 may over dry because the average velocities above the tray are higher than others tray. The simulation result of $3 \mathrm{D}$ streamline is shown in Fig. 6. Based on the streamline color, it shows that the air velocity is higher at the areas that close to the inlet and outlet. The air velocity is low along the tray because the air was distributed to all the trays at different levels. The average air velocity at the upper tray is highest because it closes to the air inlet and outlet.

Mesh adaption was performed in this simulation work to ensure the solution is mesh independent and to obtain more accurate result. In the future experimental work, several positions in the drying chamber have to be installed with temperature, velocity and humidity sensors to validate the simulation data.

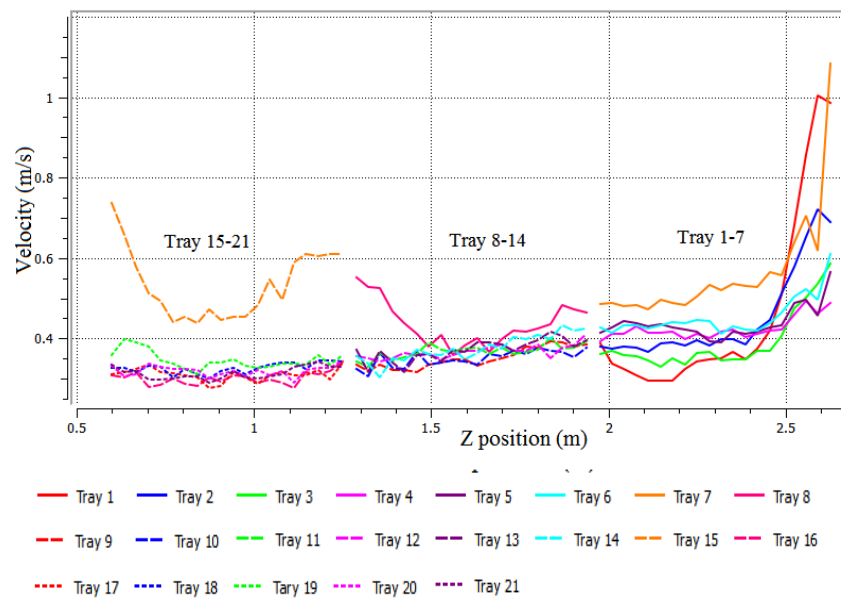

Fig. 5. Air velocity against tray positions (along $\mathrm{Z}$ axis) for each tray.

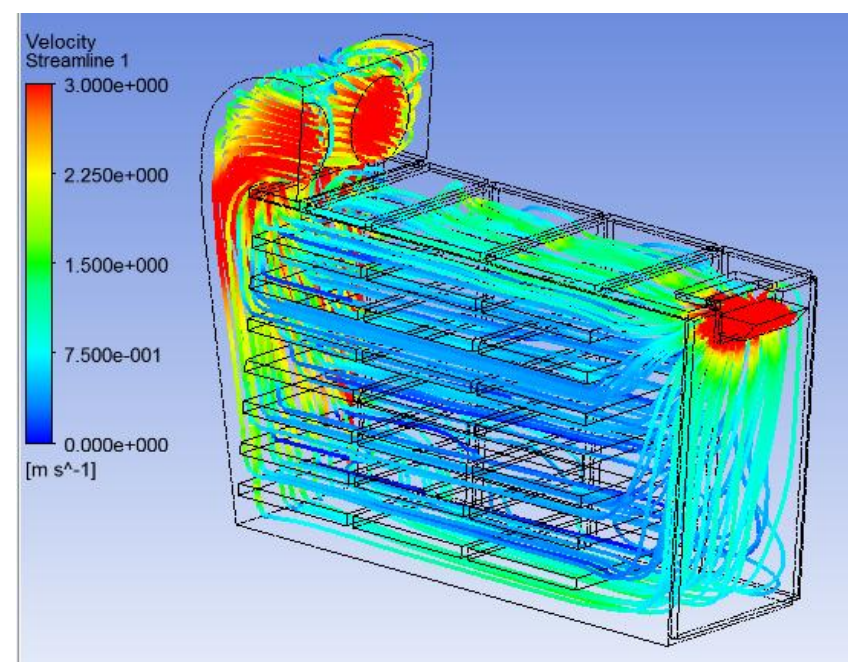

Fig. 6. 3D streamline in the drying chamber.

\section{CONCLUSION}

Tray dryer is the most extensively used because of its simple and economic design. The main drawback of tray dryer is the non-uniformity of the final moisture content of the product. Good air flow distribution throughout the drying chamber can improve the drying uniformity. CFD is considered an integral part of engineering design and analysis because of its capability to solve equations for the conservation of mass, momentum, and energy using numerical methods to predict the temperature, velocity, and pressure profiles in the drying chamber. Therefore the performance of new dryer designs may be predicted by simulation work. The results shows that there are some product will experience high air velocity, product at tray number $1,7,8$ and 15 . The average air velocity above the tray is about $0.38 \mathrm{~m} / \mathrm{s}$. Generally the temperatures are considered uniform for all trays. The new design of dryer is suitable for agricultural drying because it can produce acceptable uniform drying at high capacity of product. The drying efficiency of this system may be increased with high air velocity inlet. The uniform drying and increasing of drying rate will also improves the quality of dried product. The uniformity of the drying may be improved by using additional baffle to direct the air flow to each tray, exchange the positions of the tray during the drying process or conducted in semi-continuous mode. However it will increases the overall cost of drying. The experimental work will be conducted in the future to validate the simulation data.

\section{ACKNOWLEDGMENT}

The authors would like to thank the Universiti Kebangsaan Malaysia, Universiti Teknikal Malaysia Melaka and Kementerian Pendidikan Malaysia for sponsoring this work.

\section{REFERENCES}

[1] S. Misha, S. Mat, M. H. Ruslan, K. Sopian, and E. Salleh, "Review on the application of a tray dryer system for agricultural products," World Applied Sciences Journal, vol. 22, no. 3, pp. 424-433, 2013.

[2] P. D. Margaris and A. G. Ghiaus, "Dried product quality improvement by air flow manipulation in tray dryers," Journal of Food Engineering, vol. 75, no. 4, pp. 542-550, Aug. 2006.

[3] E. Mathioulakis, V. T. Karathanos, and V. G. Belessiotis, "Simulation of air movement in a dryer by computational fluid dynamics: Application for the drying of fruits," Journal of Food Engineering, vol. 36, no. 2, pp. 183-200, May 1998.

[4] P. S. Mirade, "Prediction of the air velocity field in modern meat dryers using unsteady computational fluid dynamics (CFD) models," Journal of Food Engineering, vol. 60, no. 1, pp. 41-48, Nov. 2003.

[5] C. Lamnatou, E. Papanicolaou, V. Belessiotis, and N. Kyriakis, "Finite-volume modelling of heat and mass transfer during convective drying of porous bodies - Non-conjugate and conjugate formulations involving the aerodynamic effects," Renewable Energy, vol. 35, no. 7, pp. 1391-1402, Jul. 2010.

[6] S. Misha, S. Mat, M. H. Ruslan, K. Sopian, and E. Salleh, "Comparison of CFD Simulation on tray dryer system between porous and solid product," presented at 7th WSEAS International Conference on Renewable Energy Sources(RES' 13), Kuala Lumpur, Malaysia, April $2^{\text {nd }}-4^{\text {th }}, 2013$.

[7] P. Verboven, N. Scheerlinck, J. De Baerdemaeker, and B. M. Nicola, "Computational fuid dynamics modelling and validation of the temperature distribution in a forced convection oven," Journal of Food Engineering, vol. 43, pp. 61-73, 2000.

[8] G. Scott and P. Richardson, "The application of computational fluid dynamics in the food industry," Trends in Food Science \& Technology, vol. 8, no. 4, pp. 119-124, Apr. 1997

[9] S. Misha, S. Mat, M. . Ruslan, and K. Sopian, "Review of solid/liquid desiccant in the drying applications and its regeneration methods," Renewable and Sustainable Energy Reviews, vol. 16, no. 7, pp 4686-4707, Sep. 2012

[10] T. Norton and D. W. Sun, "Computational fluid dynamics (CFD) - an effective and efficient design and analysis tool for the food industry: A review," Trends in Food Science \& Technology, vol. 17, no. 11, pp. 600-620, Nov. 2006.

[11] O. Yongson, I. A. Badruddin, Z. A. Zainal, and P. A. Aswatha Narayana, "Airflow analysis in an air conditioning room," Building and Environment, vol. 42, no. 3, pp. 1531-1537, Mar. 2007. 


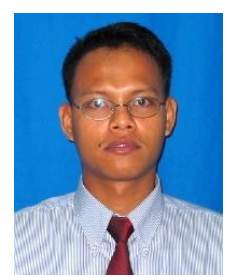

Suhaimi Misha is a graduate. He got bachelor of Engineering (Hons) degree in Mechanical and Materials Engineering from Universiti Kebangsaan Malaysia in 1999, and master of Engineering (Mechanical) from Universiti Teknologi Malaysia in 2006. Currently, he is pursuing Ph.D. study in the field of solar drying at Universiti Kebangsaan Malaysia. His research interests are solar energy technology and solar drying.

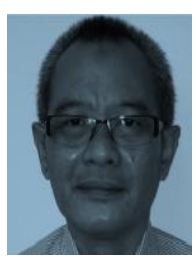

Sohif Mat is a graduate. He got the bachelor of Engineering (Hons) degree in Mechanical in 1983 and Ph.D. in Combustion in 1990 from Universiti Malaya, Malaysia. Currently, he serves as a professor and principal research fellow at Solar Energy Research Institute, Universiti Kebangsaan Malaysia. His research interests are low energy architecture and indoor environmental quality.

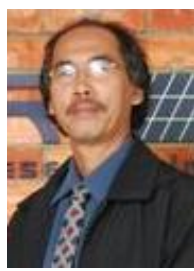

Mohd Hafidz Ruslan is a graduate. He got bachelor of Sciences degree in Physics in 1987, master of Sciences in Physics in 1994 and Ph.D. in Physics in 2001 from Universiti Kebangsaan Malaysia. Currently, he serves as a deputy director at Solar Energy Research Institute, Universiti Kebangsaan Malaysia. His research interests are solar energy technology, solar thermal and solar drying.

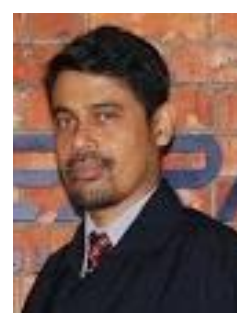

Kamaruzzaman Sopian is a graduate. He got bachelor in Mechanical Engineering from University of Wisconsin-Madison in 1985, master in Energy Resources from University of Pittsburgh in 1989 and Ph.D. in Mechanical Engineering (Solar Energy) from University of Miami-Coral Gables in 1997. Currently, he serves as a professor and director at Solar Energy Research Institute, Universiti Kebangsaan Malaysia. His research interests are solar energy technology, wind energy technology, fuel cell technology and fluidized bed combustion.

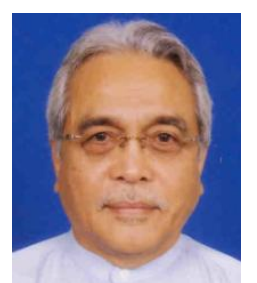

Elias Salleh is a graduate. He got diploma in Building Design from Technical College Kuala Lumpur in 1969, bachelor in Architecture from University of Plymouth UK in 1973, master in Building Science from University of Sydney Australia in 1981 and Ph.D. in Architecture from Architectural Association (AA) Graduate School London in 1994. Currently, he serves as a professor and principal research fellow at Solar Energy Research Institute, Universiti Kebangsaan Malaysia. His research interests are low energy architecture. 